ORIGINAL ARTICLE

\title{
Laboratory work and pregnancy outcomes: a study within the National Birth Cohort in Denmark
}

\author{
J L Zhu, L E Knudsen, A-M N Andersen, N H Hiollund, J Olsen
}

Occup Environ Med 2006;63:53-58. doi: 10.1136/oem.2005.021204

See end of article for authors' affiliations .....................

Correspondence to: Dr J L Zhu, The Danish Epidemiology Science Centre, University of Aarhus, Vennelyst Boulevard 6, DK 8000 Aarhus C, Denmark; zj|@soci.au.dk

Accepted 22 August 2005

\begin{abstract}
Aims: To examine pregnancy outcomes in women doing laboratory work.
Methods: Using data from the Danish National Birth Cohort (1997-2003), the authors conducted a prospective cohort study of 1025 female laboratory technicians and 8037 female teachers (as reference). The laboratory technicians were asked about laboratory work tasks during pregnancy in an interview (at around 16 weeks of gestation). Pregnancy outcomes were obtained by linking the cohort to the national registers. Hazard ratios (HRs) of late fetal loss and diagnosing of congenital malformations were calculated by using Cox regression, and odds ratios (ORs) of preterm birth and small for gestational age were calculated by using logistic regression.

Results: Overall, there were no significant differences in pregnancy outcomes between laboratory technicians and teachers. However, we found that laboratory technicians working with radioimmunoassay or radiolabelling had an increased risk of preterm birth $(O R=2.2,95 \% \mathrm{Cl} 0.8$ to 6.2 for radioimmunoassay, and $\mathrm{OR}=1.9,95 \% \mathrm{Cl} 0.8$ to 4.6 for radiolabelling) and "major" malformations ( $\mathrm{HR}=2.1,95 \% \mathrm{Cl} 1.0$ to 4.7 for radioimmunoassay, and $\mathrm{HR}=1.8,95 \% \mathrm{Cl} 0.9$ to 3.7 for radiolabelling). The ORs of preterm birth doubled for women working with these tasks every day or several times a week. When an exposure matrix was applied, an increased risk of "major" malformations for exposure to organic solvents was seen.

Conclusions: The results did not indicate any high risk of reproductive failures in laboratory technicians in general. Exposure to radioisotopes may carry a high risk of preterm birth and congenital malformations. This finding deserves further investigation.
\end{abstract}

a aboratory technicians are often in contact with chemicals, such as organic solvents, dyes, and radioactive isotopes, -which carry potential adverse effects on reproduction. ${ }^{1}$ Most studies have investigated the risk of spontaneous abortion or malformations for laboratory work, in particular for exposure to organic solvents..$^{3-12}$ In a review, Lindbohm concluded that high exposure to solvents may increase the risk of spontaneous abortion. ${ }^{13}$ Following that paper, a metaanalysis showed a slightly increased risk of spontaneous abortion (OR 1.25 , 95\% CI 0.99 to 1.58 ) or major malformations (OR 1.64, 95\% CI 1.16 to 2.30 ) for maternal solvent exposure during the first trimester of pregnancy. ${ }^{14}$ Later, a prospective study corroborated the increased risk of major malformations in relation to gestational exposure to organic solvents (RR 13.0, 95\% CI 1.8 to 99.5), ${ }^{15}$ but the difference in previous miscarriage rate between the two comparison groups $(51 \% \vee 20 \%)$ raised questions on the validity of the finding. ${ }^{16}{ }^{17}$ Recently, Wennborg and colleagues found that exposure to solvents increased the risk of preterm birth as well as "major" malformations in women working in biomedical laboratories. ${ }^{12} 18$

Most studies have used retrospective data on exposure, which is vulnerable to recall bias, in particular when many different chemicals were used in laboratories. The laboratory environment is often characterised by rapid changes in techniques. ${ }^{211}$ Previously we found no significant differences in time to pregnancy among women performing different work tasks in laboratory. ${ }^{19}$ In this study we used a follow up study design to examine whether exposure to laboratory work tasks or exposure to substances assessed by a job exposure matrix had an increased risk of preterm birth, small for gestational age, or congenital malformations.

\section{SUBJECTS AND METHODS}

\section{Study population}

The study was carried out within the Danish National Birth Cohort (DNBC). ${ }^{20}{ }^{21}$ All pregnant women who spoke Danish well enough to take part in the interviews were invited to join the cohort if they attended a general practitioner (GP) who took part in the recruitment (about $60 \%$ of all GPs). About $60 \%$ of those invited women eventually consented to participate in the cohort. From June 1997 to February 2003, 82149 women (88 915 pregnancies: 6527 women contributed with more than one pregnancy) were interviewed in the first of four telephone interviews (two prenatal and two postnatal) as part of the data collection to the cohort. We identified 1069 pregnancies of laboratory technicians who worked in laboratories of hospitals, universities, medical industry, food industry, or public services at the time of the first interview. We used 8461 pregnancies of teachers from the cohort as a reference group, because they have similar income and education. They were selected according to job titles reported by the women in the first interview. Both laboratory technicians and teachers occupied only one job at the time of the interview. If a woman participated in the study with more than one pregnancy during the study period we included the first pregnancy only (42 pregnancies for laboratory technicians and 397 for teachers were thus excluded). We also excluded pregnancies terminated by induced abortion (one for laboratory technicians and 20 for teachers), hydatidiform mole ( 0 for laboratory technicians

Abbreviations: DISCO, Danish Version of International Standard Classification of Occupation; DNA, deoxyribonucleic acid; DNBC, the Danish National Birth Cohort; RNA, ribonucleic acid 
and two for teachers), or pregnancies of unknown outcomes because of emigration or other reasons (one for laboratory technicians and five for teachers). Finally, 1025 pregnancies of laboratory technicians and 8037 pregnancies of teachers were available for the analysis.

\section{Exposure assessment}

The laboratory technicians were asked in the first interview (gestational week 11-25 with a median of week 16) about their laboratory work processes during pregnancy and three months before pregnancy. They were asked about the frequencies of work processes, and whether protective measures were used at work. The questions on laboratory work, together with a job exposure matrix, were similar to a previous Danish survey of industrial technicians in $1980 .{ }^{22} 23$ The exposure quantification in the job exposure matrix ${ }^{19}$ was adjusted to the present working situation according to the experience of present laboratory work by two authors of the study with the exposure matrix. ${ }^{22}$ We used an exposure index (EI) for each exposure, which was calculated as follows: $\mathrm{EI}=\mathrm{EL} \times \mathrm{F}$, where $\mathrm{EL}=$ exposure level (based on the job exposure matrix $^{19}$ ), low $=1$, medium $=2$, and high $=3$; $\mathrm{F}=$ frequency of work contacts, every day $=4$, several times per week $=3$, several days per month $=2$, and more rare $=1$. We then grouped them, according to frequencies of EI, into two exposure levels: 1-5 and 6+. A cut off of more than $90 \%$ index of each exposure was also used to define a high exposure group.

\section{Measurement of outcome}

Pregnancy outcomes were obtained by linking the cohort to the National Hospital Register and the Medical Birth Register by means of the unique personal identification number (civil registration number) which is assigned to all residents in Denmark at the time of birth or the time of immigration. The National Hospital Register entails data on all hospital admissions, outpatients, and emergency ward contacts. ${ }^{24}$ All pregnancy outcomes, including fetal loss and live births, are reported to this register. Congenital malformations (DQ00DQ99) are recorded in this register based on the International Classification of Diseases, Version 10. "Major" malformations define all malformations that remain after excluding accessory auricle (DQ170), undescended testicle (DQ53), hip dislocation (DQ650-DQ656), and pigmented nevus (DQ825). ${ }^{12}$ The Medical Birth Register comprises data, including birth weight, on all live births and stillbirths by women with permanent residence in Denmark. ${ }^{25}$ If the registers contained no information on the pregnancy, we used information in the interviews or obtained by phoning the mother $(<1 \%)$.

We studied late fetal loss (late spontaneous abortion and stillbirth), multiple births, sex ratio (being a male infant), preterm ( $<37$ weeks of gestation) and very preterm birth $(<34$ weeks of gestation), small for gestational age $(<$ the 10th percentile of the sex and gestation specific birth weight in the DNBC), and congenital malformations. Gestational age at birth was estimated by three sources: the last menstrual period provided in the consent form $(95.9 \%)$, the expected date of delivery given in the second interview (3.6\%), and the gestational age registered in the National Hospital Register $(0.5 \%){ }^{26}$ There was no substantial difference in how the gestational age was determined for laboratory technicians and for teachers.

\section{Statistical analysis}

Hazard ratios (HRs) of late fetal loss and diagnosing of congenital malformations were calculated by using Cox regression. For fetal loss, follow up started from the date of the first interview and ended at the time of fetal loss or delivery (Cox regression with left truncation). For congenital malformations, follow up started from the date of birth and ended at the time of diagnosing of a malformation or the end of follow up (9 November 2004). Odds ratios (ORs) of other outcomes were calculated by using logistic regression. First, HRs of fetal loss and congenital malformations and ORs of other outcomes for laboratory technicians were calculated compared with teachers. Then, HRs of major malformations and ORs of preterm birth and small for gestational age were calculated for laboratory technicians working with a specific work process in a comparison with those technicians who did not work with this process, but could work with one or more other processes. Similar comparisons on the exposure to specific substances based on the job-exposure matrix were made within laboratory technicians, restricted to laboratory technicians who had a liveborn singleton $(n=991)$. A test for trend on the effects of exposure levels (exposure frequencies, or exposure indexes) on the examined outcomes was performed using group categories of exposure levels as ordinal numbers in the full model. A p value $<0.05$ was considered statistically significant.

Potential confounders included maternal age, gravidity, history of spontaneous abortion, prepregnancy body mass index, smoking, alcohol consumption, and paternal laboratory job. Sex of child was also included for the analyses on preterm and very preterm birth, and congenital malformations. Paternal job was classified according to the Danish Version of International Standard Classification of Occupation (DISCO-88) 27 into laboratory job $(2113,2211-$ 2213, 3111-3114, 3116, 3211-3212) and non-laboratory job, together with two additional categories (unemployed and information missing). Cox regressions were performed in STATA 8.0 (STATA Corp, College Station, TX, USA), and all other analyses were conducted in SPSS 10.0 (SPSS Inc, Chicago, IL, USA).

\section{RESULTS}

The characteristics of the participants are shown in table 1. Compared with teachers, the laboratory technicians were younger and less often smokers. Both laboratory technicians and teachers had a similar proportion of pregnancies following treatment for infertility $(8.0 \% \vee 6.7 \%)$. Gravidity and a history of spontaneous abortion did not differ between the two groups. The median follow up time in the analysis of congenital malformations was 4.3 years for laboratory technicians and 3.8 years for teachers.

Compared with teachers, laboratory technicians had similar pregnancy outcomes (table 2). Among singletons, the mean birth weight and gestational age at birth were similar between children of laboratory technicians and teachers (3603 (SD 525) g and 281 (SD 12) days for laboratory technicians, and 3619 (SD 562) g and 281 (SD 12) days for teachers).

The comparisons within laboratory technicians showed that working with radioimmunoassay or radiolabelling had the highest OR for preterm birth (table 3), and that the increased risk was restricted to the frequently exposed groups (table 4). Technicians working with these two tasks also showed the highest HR for major malformations (table 3). The majority of these malformations were congenital deformations of the musculoskeletal system. The risk estimates for major malformations were similar for women working with the tasks either frequently or less frequently (table 4). There were 22 technicians performing both tasks frequently. They had an OR of 6.9 (95\% CI 2.1 to 23.2 ) for preterm birth and an HR of 2.4 (95\% CI 0.7 to 7.9 ) for major malformations, and their children had significantly lower mean birth weight than children of technicians not working with these two tasks (3374 (SD 587) g v 3609 (SD 527) g). 


\begin{tabular}{|c|c|c|c|c|}
\hline & \multicolumn{2}{|c|}{$\begin{array}{l}\text { Laboratory } \\
\text { technicians }\end{array}$} & \multicolumn{2}{|c|}{ Teachers } \\
\hline & $\mathbf{n}$ & $\%$ & $\mathbf{n}$ & $\%$ \\
\hline Total & 1025 & 100.0 & 8037 & 100.0 \\
\hline \multicolumn{5}{|l|}{ Maternal age, years } \\
\hline$<30$ & 531 & 51.8 & 3801 & 47.3 \\
\hline $30-34$ & 395 & 38.5 & 3064 & 38.1 \\
\hline $35+$ & 99 & 9.7 & 1172 & 14.6 \\
\hline \multicolumn{5}{|l|}{ Gravidity } \\
\hline 0 & 396 & 38.6 & 2891 & 36.0 \\
\hline $1+$ & 629 & 61.4 & 5143 & 64.0 \\
\hline Missing & 0 & 0.0 & 3 & 0.0 \\
\hline \multicolumn{5}{|c|}{$\begin{array}{l}\text { History of spontaneous } \\
\text { abortion* }\end{array}$} \\
\hline Yes & 174 & 27.7 & 1522 & 29.6 \\
\hline No & 455 & 72.3 & 3618 & 70.3 \\
\hline Missing & 0 & 0.0 & 3 & 0.1 \\
\hline \multicolumn{5}{|l|}{ Smoking } \\
\hline Yes & 153 & 14.9 & 1773 & 22.1 \\
\hline No & 872 & 85.1 & 6260 & 77.9 \\
\hline Missing & 0 & 0.0 & 4 & 0.0 \\
\hline \multicolumn{5}{|c|}{$\begin{array}{l}\text { Alcohol consumption (units } \\
\text { per week)t }\end{array}$} \\
\hline No & 512 & 50.0 & 4446 & 55.3 \\
\hline $0.5-1$ & 360 & 35.1 & 2466 & 30.7 \\
\hline$>1$ & 153 & 14.9 & 1119 & 13.9 \\
\hline Missing & 0 & 0.0 & 6 & 0.1 \\
\hline \multicolumn{5}{|c|}{$\begin{array}{l}\text { Prepregnancy body mass } \\
\text { index }\left(\mathrm{kg} / \mathrm{m}^{2}\right)\end{array}$} \\
\hline$<18.5$ & 43 & 4.2 & 213 & 2.7 \\
\hline $18.5-30$ & 903 & 88.1 & 7072 & 88.0 \\
\hline$>30$ & 67 & 6.5 & 629 & 7.8 \\
\hline Missing & 12 & 1.2 & 123 & 1.5 \\
\hline \multicolumn{5}{|l|}{ Paternal job } \\
\hline Laboratory & 65 & 6.3 & 173 & 2.2 \\
\hline Non-laboratory & 781 & 76.2 & 6816 & 84.8 \\
\hline No job & 54 & 5.3 & 684 & 8.5 \\
\hline Missing & 125 & 12.2 & 364 & 4.5 \\
\hline
\end{tabular}

*Among women with previous pregnancies.

†One unit of alcohol equals one glass of wine or one bottle of beer $(12 \mathrm{~g}$ alcohol).

When an exposure matrix was applied, exposure to experimental animals and to organic solvents had the highest risk estimates of major malformations, with test for trend $\mathrm{p}=0.047$ and 0.259 , respectively (table 5). However, when the analyses were further adjusted for all other substances in the table, only exposure to organic solvents showed a significant high risk estimate for major malformations, HR
3.5 (95\% CI 0.9 to 13.6) for exposure index of 1-5, and HR 4.5 (95\% CI 1.3 to 16.2 ) for exposure index of $6+$, with test for trend $p=0.025$. There seemed to be clusters of congenital deformations of the musculoskeletal system in connection to exposure to organic solvents (table 6). We obtained similar results when we defined the high level exposure group as more than $90 \%$ of exposure index, although high exposure to radioisotopes ( $>8$ exposure index) or organic solvents $(>25$ exposure index) had an increased risk of preterm birth (OR $1.7,95 \%$ CI 0.6 to 4.4 , and OR 3.1, 95\% CI 0.9 to 11.0 , respectively).

The crude and the adjusted risk estimates were almost the same (tables 2-5). When analyses were restricted to women who were pregnant for the first time, HR of major malformations for work with radioimmunoassay or radiolabelling were reduced with a wider $95 \%$ confidence interval (HR $0.8,95 \%$ CI 0.1 to 6.2 and HR $1.4,95 \%$ CI 0.3 to 6.1 , respectively). When we excluded pregnancies after treatment for infertility, the slightly increased risk of multiple births for laboratory technicians disappeared (OR $0.8,95 \%$ CI 0.4 to 1.7). The results did not change with respect to other exposures and outcomes under study (data not shown).

\section{DISCUSSION}

Laboratory work in general did not show any significant associations with the studied pregnancy outcomes, which is in line with results of recent studies from Sweden ${ }^{11}{ }^{12}$ and results of previous studies from Denmark. ${ }^{78}$ Furthermore, no significant differences in late fetal loss, preterm birth and very preterm birth, or small for gestational age were seen for laboratory technicians, compared with all the daytime workers in the DNBC (the corresponding incidences were $1.2 \%$, $4.2 \%, 1.1 \%$, and $9.6 \%$, respectively). ${ }^{26}{ }^{28}$ However, we found that laboratory technicians working with radioimmunoassay or radiolabelling had an increased risk for preterm birth and for "major" malformations, and that exposure to organic solvents in laboratories was associated with an increased risk for preterm birth and for "major" malformations. These "positive" findings were based on a number of subanalyses, and thus must be interpreted cautiously.

Our findings on radioisotopes were in conflict with the results of the Swedish studies that showed no increased risk of preterm birth or "major" malformations. ${ }^{12}{ }^{18}$ In addition, the monitoring data on the radioisotopes from the National Institute of Radiation Hygiene did not show excess exposure for the laboratory workers who were at potential risk of exposure to radioisotopes. ${ }^{19}$ No conclusion has been reached

Table 2 Pregnancy outcomes for laboratory technicians and teachers (reference)

\begin{tabular}{|c|c|c|c|c|c|c|}
\hline & \multicolumn{2}{|c|}{$\begin{array}{l}\text { Teachers } \\
(\mathrm{n}=8037)\end{array}$} & \multicolumn{4}{|c|}{ Laboratory technicians ( $n=1025$ ) } \\
\hline & $\mathbf{n}$ & (\%) & $\mathbf{n}$ & (\%) & Crude HR/OR & $\begin{array}{l}\text { Adjusted HR/OR } \\
(95 \% \mathrm{Cl})\end{array}$ \\
\hline Late fetal loss & 106 & 1.3 & 9 & 0.9 & 0.7 & $0.7(0.4$ to 1.4$)$ \\
\hline Multiple births* & 153 & 1.9 & 25 & 2.5 & 1.3 & $1.4(0.9$ to 2.1$)$ \\
\hline Male infant† & 3970 & 51.0 & 502 & 50.7 & 1.0 & $1.0(0.9$ to 1.1$)$ \\
\hline Preterm birth† & 317 & 4.1 & 41 & 4.1 & 1.0 & $1.1(0.8$ to 1.5$)$ \\
\hline Very preterm birth $\dagger$ & 78 & 1.0 & 9 & 0.9 & 0.9 & $1.0(0.5$ to 2.0$)$ \\
\hline Small for gestational age †‡ & 700 & 9.2 & 80 & 8.2 & 0.9 & $0.9(0.7$ to 1.2$)$ \\
\hline All malformations $\dagger$ & 494 & 6.4 & 69 & 7.0 & 1.1 & $1.1(0.8$ to 1.4$)$ \\
\hline "Major" malformations $\dagger$ & 379 & 4.9 & 56 & 5.7 & 1.1 & $1.1(0.9$ to 1.5$)$ \\
\hline
\end{tabular}

Cox regression for fetal loss and congenital malformations, HR: hazard ratio; logistic regression for other outcomes, OR: odds ratio; Cl: confidence interval; adjusted for maternal age, gravidity, history of spontaneous abortion, prepregnancy body mass index, smoking, alcohol consumption, and paternal job (as well as sex of child for preterm, very preterm birth, and congenital malformations).

*Among live births.

†Among singletons.

fExcluding births without information on birth weight for laboratory technicians $(n=12)$ and teachers $(n=132)$. 
Table 3 Preterm birth, small for gestational age, and major malformations for working with specific processes among laboratory technicians $(n=991)$

\begin{tabular}{|c|c|c|c|c|c|c|c|c|c|c|}
\hline \multirow[b]{2}{*}{ Work process } & \multirow[b]{2}{*}{$\begin{array}{l}\text { Births, } \\
\text { n }\end{array}$} & \multicolumn{3}{|c|}{ Preterm birth } & \multicolumn{3}{|c|}{ Small for gestational age } & \multicolumn{3}{|c|}{ "Major" malformations } \\
\hline & & n $(\%)$ & $\begin{array}{l}\text { Crude } \\
\text { OR }\end{array}$ & $\begin{array}{l}\text { Adjusted OR } \\
(95 \% \mathrm{Cl})\end{array}$ & n (\%) & $\begin{array}{l}\text { Crude } \\
\text { OR }\end{array}$ & $\begin{array}{l}\text { Adjusted OR } \\
\text { (95\% Cl) }\end{array}$ & n $(\%)$ & $\begin{array}{l}\text { Crude } \\
\text { HR }\end{array}$ & $\begin{array}{l}\text { Adjusted HR } \\
(95 \% \mathrm{CI})\end{array}$ \\
\hline Chromatography & 205 & $12(5.9)$ & 1.6 & $1.6(0.8$ to 3.3$)$ & $21(10.4)$ & 1.4 & $1.3(0.7$ to 2.2$)$ & $8(3.9)$ & 0.6 & $0.7(0.3$ to 1.4$)$ \\
\hline Photometry & 238 & $9(3.8)$ & 0.9 & $0.8(0.4$ to 1.7$)$ & $19(8.0)$ & 1.0 & $1.0(0.6$ to 1.7$)$ & $14(5.9)$ & 1.1 & $1.0(0.6$ to 1.9$)$ \\
\hline Electrophoreses & 167 & $7(4.2)$ & 1.0 & $0.9(0.4$ to 2.2$)$ & $14(8.4)$ & 1.1 & $1.0(0.5$ to 1.8$)$ & $9(5.4)$ & 0.9 & $1.0(0.5$ to 2.1$)$ \\
\hline Extraction (eg hormones) & 130 & $7(5.4)$ & 1.4 & $1.5(0.6$ to 3.5$)$ & $14(10.8)$ & 1.4 & $1.5(0.8$ to 2.8$)$ & $7(5.4)$ & 1.0 & $0.9(0.4$ to 2.0$)$ \\
\hline Radiolabelling & 96 & $7(7.3)$ & 2.0 & $1.9(0.8$ to 4.6$)$ & $11(11.6)$ & 1.5 & $1.6(0.8$ to 3.2$)$ & $9(9.4)$ & 1.8 & $1.8(0.9$ to 3.7$)$ \\
\hline Radioimmunoassay & 61 & $5(8.2)$ & 2.2 & $2.2(0.8$ to 6.2$)$ & $4(6.6)$ & 0.8 & $0.8(0.3$ to 2.3$)$ & 7 (11.5) & 2.2 & $2.1(1.0$ to 4.7$)$ \\
\hline Enzyme techniques & 285 & $5(1.8)$ & 0.3 & $0.3(0.1$ to 0.8$)$ & $21(7.4)$ & 0.9 & $0.9(0.5$ to 1.5$)$ & $12(4.2)$ & 0.7 & $0.7(0.4$ to 1.3$)$ \\
\hline Human blood/tissue processing & 338 & $12(3.6)$ & 0.8 & $0.8(0.4$ to 1.6$)$ & $24(7.2)$ & 0.8 & $0.8(0.5$ to 1.3$)$ & $22(6.5)$ & 1.2 & $1.2(0.7$ to 2.1$)$ \\
\hline Working with animals & 70 & $1(1.4)$ & 0.3 & $0.3(0.0$ to 2.3$)$ & $8(11.6)$ & 1.5 & $1.6(0.7$ to 3.5$)$ & $6(8.6)$ & 1.6 & $1.7(0.7$ to 4.0$)$ \\
\hline Working with microorganisms & 251 & $11(4.4)$ & 1.1 & $1.2(0.6$ to 2.4$)$ & $18(7.2)$ & 0.8 & $0.8(0.5$ to 1.4$)$ & $12(4.8)$ & 0.8 & $0.8(0.4$ to 1.6$)$ \\
\hline Preparation of slides & 215 & 7 (3.3) & 0.8 & $0.7(0.3$ to 1.7$)$ & $21(9.8)$ & 1.3 & $1.3(0.8$ to 2.3$)$ & $15(7.0)$ & 1.3 & $1.3(0.7$ to 2.4$)$ \\
\hline RNA or DNA isolation & 70 & $4(5.7)$ & 1.4 & $1.7(0.6$ to 4.9$)$ & $3(4.3)$ & 0.5 & $0.5(0.1$ to 1.5$)$ & $4(5.7)$ & 1.0 & $1.2(0.4$ to 3.2$)$ \\
\hline Organic-chemical processes & 195 & $9(4.6)$ & 1.2 & $1.2(0.5$ to 2.6$)$ & $15(7.7)$ & 0.9 & $0.8(0.5$ to 1.5$)$ & $10(5.1)$ & 0.9 & $1.0(0.5$ to 1.9$)$ \\
\hline Organic synthesis & 65 & $2(3.1)$ & 0.7 & $0.7(0.2$ to 3.0$)$ & $3(4.6)$ & 0.5 & $0.5(0.2$ to 1.7$)$ & $0(0.0)$ & NA & NA \\
\hline Inorganic synthesis & 66 & $1(1.5)$ & 0.3 & $0.3(0.0$ to 2.2$)$ & $4(6.1)$ & 0.7 & $0.7(0.3$ to 2.1$)$ & $2(3.0)$ & 0.5 & $0.4(0.1$ to 1.7$)$ \\
\hline
\end{tabular}

Cox regression for major malformations, HR: hazard ratio; logistic regression for preterm birth and small for gestational age, OR: odds ratio; adjusted for maternal age, gravidity, history of spontaneous abortion, prepregnancy body mass index, smoking, alcohol consumption, paternal job, and sex of child; $\mathrm{Cl}$ : confidence interval; reference group for each work process was laboratory technicians not working with the particular work process.

on the risk of the low dose radioactive exposure on reproductive failures, ${ }^{29-32}$ and our findings could be due to ionising radiation, confounding, or chance. Cases of preterm birth and cases of congenital malformations did not overlap. Furthermore, we found that the risk of preterm birth followed to some extent a dose-response pattern, but this was not seen for congenital malformations. This may reflect that peak exposure in the critical time window of organogenesis is more important than the average exposure level. Although these subanalyses were part of the study protocol, further studies are needed to clarify the risks for these work processes.

Our results on organic solvents were in line with studies from Sweden, ${ }^{12}{ }^{18}$ which showed an association with preterm birth (OR 3.4, 95\% CI 1.0 to 11.9) and "major" malformations (OR $1.8,95 \%$ CI 1.0 to 2.9). A number of studies indicate an association between high exposure to organic solvents and preterm birth, spontaneous abortion, or malformations. ${ }^{12-15} 18$ We were not able to further look into the risk of late fetal loss for different work processes or substances (including organic solvents) due to the small number of cases $(n=9)$.

The DNBC recruited about $30-40 \%$ of all pregnant women in Denmark during the study period, with about $60 \%$ of those invited women eventually participating in the cohort. A selection bias may operate if laboratory technicians and teachers had different participation rates regarding the outcomes under study, which is unlikely because we collected exposure information before the outcome was known. We had almost complete follow up based upon the register linkages, and thus the results are not biased by differential losses to follow up.

Even though the exposed population (laboratory technicians) is larger than most previous studies, we lacked power to detect small or moderate increased risks of rare outcomes, in particular in relation to uncommon exposures in the laboratory. It must be remembered that we investigated fetal loss only after the first interview, which was around 16 weeks of gestation. If an exposure leads to early abortion, we were not able to detect such effect. The prevalences of congenital malformations were higher compared with most other studies, ${ }^{12}{ }^{33}$ due to the longer follow up time for diagnosing congenital malformations in our study. When we restricted diagnoses to the first month since birth (similar to the Swedish study ${ }^{12}$ ), the prevalences of "major" malformation were $2.5 \%$ for laboratory technicians and $2.1 \%$ for teachers, which is similar to $2.3 \%$ for laboratory technicians and $1.9 \%$ in the reference group in the Swedish study. ${ }^{12}$ This reduction (about $50 \%$ ) is related to all organ systems.

Table 4 Preterm birth and major malformations for working with radiolabelling or radioimmunoassay according to exposure levels, among laboratory technicians $(n=991)$

\begin{tabular}{|c|c|c|c|c|c|c|c|}
\hline \multirow[b]{2}{*}{ Work process and exposure level } & \multirow[b]{2}{*}{ Births, $n$} & \multicolumn{3}{|c|}{ Preterm birth } & \multicolumn{3}{|c|}{ "Major" malformations } \\
\hline & & $n(\%)$ & Crude OR & Adjusted OR $(95 \% \mathrm{Cl})$ & $n(\%)$ & Crude HR & Adjusted HR $(95 \% \mathrm{Cl})$ \\
\hline \multicolumn{8}{|l|}{ Radiolabelling } \\
\hline No & 891 & $34(3.8)$ & 1.0 & 1.0 & $47(5.3)$ & 1.0 & 1.0 \\
\hline Less frequently* & 55 & $3(5.5)$ & 1.5 & $1.2(0.3$ to 4.2$)$ & $5(9.1)$ & 1.7 & $1.8(0.7$ to 4.5$)$ \\
\hline Frequently $\dagger$ & 40 & $4(10.0)$ & 2.8 & $3.5(1.1$ to 11.0$)$ & $4(10.0)$ & 1.9 & $1.8(0.7$ to 5.1$)$ \\
\hline \multirow{2}{*}{\multicolumn{8}{|c|}{ Radioimmunoassay }} \\
\hline & & & & & & & \\
\hline No & 926 & $36(3.9)$ & 1.0 & 1.0 & $49(5.3)$ & 1.0 & 1.0 \\
\hline Less frequently* & 32 & $1(3.1)$ & 0.8 & $0.7(0.1$ to 5.3$)$ & $4(12.5)$ & 2.4 & $2.3(0.8$ to 6.6$)$ \\
\hline Frequently† & 29 & $4(13.8)$ & 4.0 & 4.8 (1.5 to 15.3$)$ & $3(10.3)$ & 1.9 & $1.9(0.6$ to 6.2$)$ \\
\hline
\end{tabular}

Logistic regression for preterm birth, OR: odds ratio; Cox regression for major malformations, HR: hazard ratio; adjusted for maternal age, gravidity, history of spontaneous abortion, prepregnancy body mass index, smoking, alcohol consumption, paternal job, and sex of child; Cl: confidence interval; numbers for each exposure do not add to $n=991$ due to missing.

*Less frequently: work with the process several days per month or more rare.

†Frequently: work with the process every day or several times per week. 
Table 5 Preterm birth, small for gestational age, and major malformations for exposures to different substances, according to an external exposure matrix, among laboratory technicians $(n=991)$

\begin{tabular}{|c|c|c|c|c|c|c|c|c|c|c|}
\hline \multirow[b]{2}{*}{ Exposure index ${ }^{*}$} & \multirow[b]{2}{*}{ Births, $n$} & \multicolumn{3}{|c|}{ Preterm birth } & \multicolumn{3}{|c|}{ Small for gestational age } & \multicolumn{3}{|c|}{ "Major" malformations } \\
\hline & & n (\%) & $\begin{array}{l}\text { Crude } \\
\text { OR }\end{array}$ & $\begin{array}{l}\text { Adjusted OR } \\
(95 \% \mathrm{CI})\end{array}$ & n (\%) & $\begin{array}{l}\text { Crude } \\
\text { OR }\end{array}$ & $\begin{array}{l}\text { Adjusted OR } \\
(95 \% \mathrm{CI})\end{array}$ & n (\%) & $\begin{array}{l}\text { Crude } \\
\text { HR }\end{array}$ & $\begin{array}{l}\text { Adjusted HR } \\
(95 \% \mathrm{CI})\end{array}$ \\
\hline \multicolumn{11}{|c|}{ Experimental animals } \\
\hline 0 & 687 & $28(4.1)$ & 1.0 & 1.0 & $53(7.8)$ & 1.0 & 1.0 & $33(4.8)$ & 1.0 & 1.0 \\
\hline $1-5$ & 234 & $10(4.3)$ & 1.1 & $1.0(0.5$ to 2.2$)$ & $20(8.5)$ & 1.1 & $1.2(0.7$ to 2.0$)$ & $17(7.3)$ & 1.5 & $1.5(0.8$ to 2.7$)$ \\
\hline $6+$ & 61 & $1(1.6)$ & 0.4 & $0.3(0.0$ to 2.7$)$ & $7(11.7)$ & 1.6 & $1.6(0.7$ to 3.7$)$ & $6(9.8)$ & 2.1 & 2.2 (0.9 to 5.2$)$ \\
\hline \multicolumn{11}{|l|}{ Epoxy substances } \\
\hline 0 & 774 & $33(4.3)$ & 1.0 & 1.0 & 59 (7.7) & 1.0 & 1.0 & $41(5.3)$ & 1.0 & 1.0 \\
\hline $1-5$ & 76 & $0(0.0)$ & NA & NA & $8(10.5)$ & 1.4 & $1.6(0.7$ to 3.5$)$ & $6(7.9)$ & 1.5 & $1.4(0.6$ to 3.4$)$ \\
\hline $6+$ & 136 & $6(4.4)$ & 1.0 & $0.9(0.4$ to 2.4$)$ & $13(9.6)$ & 1.3 & $1.2(0.6$ to 2.4$)$ & $9(6.6)$ & 1.2 & $1.3(0.6$ to 2.6$)$ \\
\hline \multicolumn{11}{|l|}{ Formaldehyde } \\
\hline 0 & 401 & $18(4.5)$ & 1.0 & 1.0 & $30(7.6)$ & 1.0 & 1.0 & $20(5.0)$ & 1.0 & 1.0 \\
\hline $1-5$ & 364 & $14(3.8)$ & 0.9 & $1.0(0.5$ to 2.0$)$ & 31 (8.7) & 1.2 & $1.2(0.7$ to 2.0$)$ & $20(5.5)$ & 1.1 & $1.2(0.6$ to 2.1$)$ \\
\hline $6+$ & 218 & $7(3.2)$ & 0.7 & $0.7(0.3$ to 1.7$)$ & 19 (8.7) & 1.2 & $1.2(0.6$ to 2.2$)$ & $16(7.3)$ & 1.5 & $1.5(0.8$ to 2.9$)$ \\
\hline \multicolumn{11}{|c|}{ 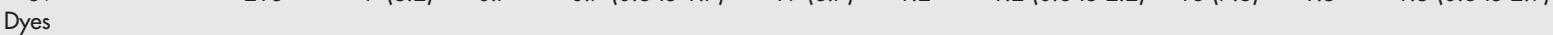 } \\
\hline 0 & 257 & $12(4.7)$ & 1.0 & 1.0 & $23(9.1)$ & 1.0 & 1.0 & $20(7.8)$ & 1.0 & 1.0 \\
\hline $1-5$ & 303 & $13(4.3)$ & 0.9 & $0.8(0.3$ to 1.8$)$ & $18(6.0)$ & 0.6 & $0.6(0.3$ to 1.2$)$ & $12(4.0)$ & 0.5 & $0.5(0.2$ to 1.0$)$ \\
\hline $6+$ & 406 & $14(3.4)$ & 0.7 & $0.7(0.3$ to 1.5$)$ & 37 (9.2) & 1.0 & $1.0(0.6$ to 1.7$)$ & $23(5.7)$ & 0.7 & $0.7(0.4$ to 1.3$)$ \\
\hline \multicolumn{11}{|l|}{ Radioisotopes } \\
\hline 0 & 426 & 20 (4.7) & 1.0 & 1.0 & $34(8.1)$ & 1.0 & 1.0 & 27 (6.3) & 1.0 & 1.0 \\
\hline $1-5$ & 354 & $11(3.1)$ & 0.7 & $0.6(0.3$ to 1.4$)$ & $25(7.1)$ & 0.9 & $0.8(0.5$ to 1.5$)$ & $15(4.2)$ & 0.7 & $0.7(0.4$ to 1.3$)$ \\
\hline $6+$ & 199 & $10(5.0)$ & 1.1 & $1.0(0.5$ to 2.3$)$ & $20(10.2)$ & 1.3 & $1.2(0.7$ to 2.2$)$ & $13(6.5)$ & 1.0 & $1.0(0.5$ to 2.0$)$ \\
\hline \multicolumn{11}{|l|}{ Heavy metals } \\
\hline 0 & 699 & $31(4.4)$ & 1.0 & 1.0 & $59(8.6)$ & 1.0 & 1.0 & 40 (5.7) & 1.0 & 1.0 \\
\hline $1-5$ & 103 & $5(4.9)$ & 1.1 & $1.0(0.4$ to 2.6$)$ & $5(4.9)$ & 0.5 & $0.5(0.2$ to 1.3$)$ & $7(6.8)$ & 1.2 & $1.2(0.5$ to 2.7$)$ \\
\hline $6+$ & 174 & $5(2.9)$ & 0.6 & $0.6(0.2$ to 1.6$)$ & $16(9.2)$ & 1.1 & $1.2(0.6$ to 2.1$)$ & $9(5.2)$ & 0.9 & $0.8(0.4$ to 1.7$)$ \\
\hline \multicolumn{11}{|l|}{ Organic solvents } \\
\hline 0 & 129 & $4(3.1)$ & 1.0 & 1.0 & $11(8.5)$ & 1.0 & 1.0 & $4(3.1)$ & 1.0 & 1.0 \\
\hline $1-5$ & 176 & $9(5.1)$ & 1.7 & $1.7(0.5$ to 6.0$)$ & $12(7.0)$ & 0.8 & $0.9(0.4$ to 2.1$)$ & $11(6.3)$ & 2.0 & $2.1(0.7$ to 6.5$)$ \\
\hline $6+$ & 641 & 25 (3.9) & 1.3 & $1.3(0.4$ to 3.9$)$ & 55 (8.7) & 1.0 & $1.0(0.5$ to 2.0$)$ & $39(6.1)$ & 2.0 & $2.0(0.7$ to 5.7$)$ \\
\hline
\end{tabular}

Cox regression for major malformations, HR: hazard ratio; logistic regression for preterm birth and small for gestational age, OR: odds ratio; adjusted for maternal age, gravidity, history of spontaneous abortion, prepregnancy body mass index, smoking, alcohol consumption, paternal job, and sex of child; $\mathrm{Cl}$ : confidence interval; reference group for exposure to each substance was laboratory technicians not exposed to the particular substance; numbers for each exposure may not add to $n=991$ due to missing; tests for trend: $p=0.256-0.888$ for all the outcomes in relation to the exposures, except for $p=0.047$ for major malformations in relation to exposure to experimental animals.

${ }^{*}$ An exposure index (EI) for each exposure was calculated as follows: $\mathrm{El}=\mathrm{EL} \times \mathrm{F}$, where $\mathrm{EL}=$ exposure level (see $\mathrm{Zhu}$ et al ${ }^{19}$ ), low $=1$, medium $=2$, and high $=3$; $\mathrm{F}=$ frequency of work contacts, every day $=4$, several times per week $=3$, several days per month $=2$, and more rare $=1$. It was then grouped into $1-5$ and $6+$.

To assess exposures in laboratory, we asked questions about laboratory work processes and used a corresponding exposure matrix. ${ }^{19} 2223$ The exposure matrix was adjusted to the present work situation, but it does not include the levels of workers' applied protection, and the validity of the exposure matrix has not been tested in a separate exposure study. The results for specific exposures to substances must thus be interpreted with caution.

Changing work conditions or being on sick leave during pregnancy could reduce exposures and lead the risk estimates

Table 6 Congenital malformations among the children of laboratory technicians according to exposure to organic solvents

\begin{tabular}{|c|c|c|c|c|c|c|c|c|}
\hline \multirow[b]{3}{*}{ "Major" malformations } & \multirow{2}{*}{\multicolumn{2}{|c|}{$\begin{array}{l}\text { All } \\
\text { technicians } \\
(n=991)\end{array}$}} & \multicolumn{6}{|c|}{ Exposure to organic solvents* } \\
\hline & & & \multicolumn{2}{|c|}{0 (n= 129) } & \multicolumn{2}{|c|}{$\begin{array}{l}1-5 \\
(n=176)\end{array}$} & \multicolumn{2}{|c|}{$6+(n=641)$} \\
\hline & $\mathbf{n}$ & $\%$ & $\mathbf{n}$ & $\%$ & n & $\%$ & n & $\%$ \\
\hline All (DQ00-DQ99) & 56 & 5.65 & 4 & 3.10 & 11 & 6.25 & 39 & 6.08 \\
\hline Nervous system (DQ00-DQ07) & 2 & 0.20 & 0 & 0.00 & 1 & 0.57 & 1 & 0.16 \\
\hline Eye, ear, face, and neck (DQ10-DQ18) & 6 & 0.61 & 1 & 0.78 & 0 & 0.00 & 5 & 0.78 \\
\hline Heart (DQ20-DQ24) & 8 & 0.81 & 1 & 0.78 & 0 & 0.00 & 7 & 1.09 \\
\hline Other circulatory system (DQ25-DQ28) & 2 & 0.20 & 0 & 0.00 & 0 & 0.00 & 2 & 0.31 \\
\hline Respiratory system (DQ30-DQ34) & 5 & 0.50 & 0 & 0.00 & 3 & 1.70 & 2 & 0.31 \\
\hline Cleft lip/palate (DQ35-DQ37) & 4 & 0.40 & 1 & 0.78 & 0 & 0.00 & 3 & 0.47 \\
\hline Hypospadias (DQ54)† & 7 & 1.39 & 1 & 1.41 & 1 & 1.16 & 5 & 1.56 \\
\hline Urinary system (DQ60-DQ64) & 3 & 0.30 & 0 & 0.00 & 0 & 0.00 & 3 & 0.47 \\
\hline Clubfoot (DQ66) & 10 & 1.01 & 0 & 0.00 & 2 & 1.14 & 7 & 1.09 \\
\hline Other congenital anomalies of limb (DQ681-DQ74) & 6 & 0.61 & 0 & 0.00 & 2 & 1.14 & 3 & 0.47 \\
\hline $\begin{array}{l}\text { Other musculoskeletal system (DQ65-DQ79, excl } \\
\text { DQ66 \& DQ681-DQ74) }\end{array}$ & 16 & 1.61 & 0 & 0.00 & 4 & 2.27 & 12 & 1.87 \\
\hline Other congenital malformations (DQ80-DQ99) & 2 & 0.20 & 0 & 0.00 & 1 & 0.57 & 1 & 0.16 \\
\hline
\end{tabular}

There were 12 cases with more than one malformation, and each malformation was counted in each relevant subgroup.

*There were 45 technicians with missing information on exposure to organic solvents due to no response to the relevant questions.

†Among boys. 


\section{Main messages}

- Working as a laboratory technician in general did not indicate any increased risks of the studied adverse pregnancy outcomes.

- Laboratory technicians working with radioisotopes may have an increased risk for preterm birth and for congenital malformations.

- Laboratory technicians working with organic solvents may have an increased risk for congenital malformations.

\section{Policy implications}

- Further investigations are warranted to clarify the risk of preterm birth and congenital malformations for working with radioisotopes in laboratories.

- When working with radioisotopes or organic solvents, laboratory technicians need to be cautious and protected from these exposures.

toward the null values. We found no difference in change of work conditions (that is, new job, new tasks) for laboratory technicians and teachers $(3.4 \% \quad v \quad 3.2 \%)$. Slightly fewer laboratory technicians took pregnancy leave of more than three days compared with teachers (36.6\% v 40.8\%). When we restricted the analyses to women who did not change their work conditions or took pregnancy leave, we obtained similar results as those presented in the tables. The majority of laboratory technicians wear protective gloves while working, but the use of local exhaust ventilation and flow bench depended on the work process.

Our results suggest that laboratory technicians working with radioimmunoassay, radiolabelling, or organic solvents had an increased risk for preterm birth and for having a child born with congenital malformations. These findings may be due to chance and further investigations are needed. Working as a laboratory technician in general did not indicate any larger risks than were seen for school teachers.

\section{ACKNOWLEDGEMENTS}

The activities of the Danish Epidemiology Science Centre are financed by grants from Danish National Research Foundation, and this work is also supported by Danish Research Agency (grant no 2202-0363), Danish Working Environmental Council, and CHILDRENGENONETWORK (QLK4-CT-2002-02198). The establishment of the Danish National Birth Cohort has been financed by the Danish National Research Foundation, Danish Pharmaceutical Association, Ministry of Health, National Board of Health, Statens Serum Institut, BIOMED, March of Dimes Birth Defects Foundation, Danish Heart Association, Danish Medical Research Council, and Sygekassernes Helsefond.

\section{Authors' affiliations}

J L Zhu, J Olsen, The Danish Epidemiology Science Centre, University of Aarhus, Aarhus, Denmark

L E Knudsen, Department of Environmental and Occupational Health, Institute of Public Health, University of Copenhagen, Copenhagen, Denmark

A-M N Andersen, National Institute of Public Health, Copenhagen, Denmark

N H Hjollund, Department of Occupational Medicine, Aarhus University Hospital, Aarhus, Denmark

J Olsen, Department of Epidemiology, School of Public Health, UCLA, Los Angeles, CA, USA

Competing interests: none.

\section{REFERENCES}

1 Emery RJ, Delclos GL. World at work: research and testing laboratories. Occup Environ Med 2005;62:200-4.

2 Dement JM, Cromer JR. Cancer and reproductive risks among chemists and laboratory workers: a review. Appl Occup Environ Hyg 1992;7:120-6.

3 Axelsson G, Lütz C, Rylander R. Exposure to solvents and outcome of pregnancy in university laboratory employees. $\mathrm{Br} J$ Ind Med 1984;41:305-12.

4 Axelsson G, Rylander R. Outcome of pregnancy in women engaged in laboratory work at a petrochemical plant. Am J Ind Med 1989;16:539-45.

5 Ericson A, Eriksson M, Källén B, et al. Delivery outcome of women working in laboratories during pregnancy. Arch Environ Health 1984;39:5-10.

6 Hansson E, Jansa S, Wande H, et al. Pregnancy outcome for women working in laboratories in some of the pharmaceutical industries in Sweden. Scand J Work Environ Health 1980;6:131-4.

7 Heidam LZ. Spontaneous abortions among laboratory workers; a follow up study. J Epidemiol Community Health 1984;38:36-41.

8 Olsen J. Risk of exposure to teratogens amongst laboratory staff and painters. Dan Med Bull 1983;30:24-8.

9 Taskinen $\mathrm{H}, \mathrm{Kyy}$ rönen $\mathrm{P}$, Hemminki K, et al. Laboratory work and pregnancy outcome. J Occup Med 1994;36:311-19.

10 Torchia MG. Report of survey: pregnancy outcomes in medical laboratory technologists. Can J Med Technol 1994;56:20-9.

11 Wennborg H, Bodin L, Vainio H, et al. Pregnancy outcome of personnel in Swedish biomedical research laboratories. J Occup Environ Med 2000;42:438-46.

12 Wennborg $\mathrm{H}$, Magnusson $L L$, Bonde JP, et al. Congenital malformations related to maternal exposure to specific agents in biomedical research laboratories. J Occup Environ Med 2005;47:1 1-9.

13 Lindbohm ML. Effects of parental exposure to solvents on pregnancy outcome. $J$ Occup Environ Med 1995;37:908-14.

14 McMartin KI, Chu M, Kopecky E, et al. Pregnancy outcome following maternal organic solvent exposure: a meta-analysis of epidemiologic studies. Am J Ind Med 1998;34:288-92.

15 Khattak S, Moghtader G, McMartin K, et al. Pregnancy outcome following gestational exposure to organic solvents: a prospective controlled study. JAMA 1999;281:1106-9.

16 Arrieta MJ, Infante-Rivard C. Organic solvent exposure during pregnancy and congenital malformations. JAMA 1999;282:1033.

17 Brent RL, Chambers CD, Chernoff GF, et al. Pregnancy outcome following gestational exposure to organic solvents: a response. Teratology 1999;60:328-31.

18 Wennborg $\mathrm{H}$, Bonde JP, Stenbeck $M$, et al. Adverse reproduction outcomes among employees working in biomedical research laboratories. Scand J Work Environ Health 2002;28:5-11.

19 Zhu JL, Knudsen LE, Andersen AM, et al. Time to pregnancy among Danish laboratory technicians who were a part of the National Birth Cohort. Scand J Work Environ Health 2005;31:108-14.

20 Olsen J, Melbye M, Olsen SF, et al. The Danish National Birth Cohort-its background, structure and aim. Scand J Public Health 2001;29:300-7.

21 The Danish National Birth Cohort. Available at http://www.bsmb.dk (accessed January 2005).

22 Knudsen LE, Vogel U. Laboratoriekemikalier og Laboratoriesikkerhed [Laboratory Chemicals and Laboratory Safety]. In: Midtgaard U, Simonsen L, Knudsen LE, eds. Kemikalier og Produkter i Arbejdsmiliøet, Bind II [Chemicals and Products in Working Environment, part II]. Copenhagen: Arbejdsmiliøinstituttet, 2000.

23 Hvid H, Banke O, Knudsen LE, et al. Industrilaboranters Arbejdsmiliø. Resultater fra en spørgeskemaundersøgelse [Working Environment in Industrial Laboratory. Results from a Questionnaire Survey]. Department of Sociology, University of Copenhagen, 1985.

24 Andersen TF, Madsen M, Jørgensen J, et al. The Danish National Hospital Register. A valuable source of data for modern health sciences. Dan Med Bull 1999:46:263-8.

25 Knudsen LB, Olsen J. The Danish Medical Birth Registry. Dan Med Bull 1998;45:320-3.

26 Zhu JL, Hiollund NH, Andersen AM, et al. Shift work, job stress, and late fetal loss: The National Birth Cohort in Denmark. J Occup Environ Med 2004;46:1 144-9.

27 DISCO-88. Statistics Denmark's Standard Classification of Occupation. Copenhagen: Danmarks Statistik, 1996.

28 Zhu JL, Hiollund NH, Olsen J. Shift work, duration of pregnancy, and birth weight: the National Birth Cohort in Denmark. Am J Obstet Gynecol 2004; 191:285-91.

29 Goldberg MS, Mayo NE, Levy AR, et al. Adverse reproductive outcomes among women exposed to low levels of ionizing radiation from diagnostic radiography for adolescent idiopathic scoliosis. Epidemiology 1998;9:271-8.

30 Kline J. Does maternal exposure to radiation before conception affect reproduction? [editorial]. Epidemiology 1998;9:231-2.

31 Grossman CM, Morton WE, Nussbaum RH. Reproductive outcomes after radiation exposure [letter]. Epidemiology 1999;10:202.

32 Goldberg MS, Mayo NE, Levy AR, et al. Reproductive outcomes after radiation exposure [author reply]. Epidemiology 1999;10:202-3.

33 Magnusson LL, Bonde JP, Olsen J, et al. Paternal laboratory work and congenital malformations. J Occup Environ Med 2004;46:761-7. 